\title{
Comparative Evaluation of Wound Outcome between Electrocautery and Scalpel Incision
}

\author{
Shri Krishna Ranjan', Santosh Kumar ${ }^{2}$ \\ ${ }^{1}$ Associate Professor, Department of Surgery, Anugrah Narayan Magadh Medical College and Hospital, Gaya, ${ }^{2}$ Assisstant Professor, Department of \\ Surgery, Anugrah Narayan Magadh Medical College and Hospital, Gaya.
}

\section{Abstract}

Background: The use of cutting electrocautery instead of scalpel for skin incision is still suboptimal worldwide. There are many studies which include its use in general surgical operations but without use of prothetic material. Aim: The objective of this study was to evaluate whether the application of extreme heat by cutting electrocautery may result in significant postoperative pain and poor wound healing with increased risk of wound infection in presence of underlying prosthetic material and poor cosmesis because of excessive tissue damage and scarring respectively as per previous hypothesis or it's safe and effective instead. Subjects and Methods: A total of 196 Patients were allocated consecutively to either electrocautery $(n=98)$ or scalpel $(n=98)$ groups. The duration used in making the skin incision; the incisional blood loss and the ensuing length and depth of the wound were noted. Postoperative pain; duration of wound healing and the occurrence of surgical site infection and cosmetic outcome were also noted. Results: The ages ranged from 16 to 73 years. The demography, case distribution and body mass index were similar in both groups. The incision time was shorter in the electrocautery group ( $\mathrm{P}<0.001)$. The blood loss was less with the electrocautery compared to the scalpel $(6.53 \pm 3.84 \mathrm{ml} \mathrm{vs} .18 .16 \pm 7.36 \mathrm{ml}, \mathrm{P}<0.001)$. The cumulative numerical rating scale score for pain was 12.65 (standard deviation SD 8.06) and 17.12 (SD 9.49) in the diathermy and scalpel groups respectively $(\mathrm{P}<0.001)$. There was no statistically significant difference in wound infection and wound closure (epithelialization time) $(\mathrm{P}=0.206)$. Conclusion: The use of cutting electrocautery in making skin incision during inguinal hernioplasty is as safe as scalpel in terms of wound healing and cosmesis and is also associated with reduced incision time, incisional blood loss, and postoperative pain.

Keywords: Surgical incision, Scalpel, Cutting electrocautery, Inguinal hernioplasty.

Corresponding Author: Dr. Santosh kumar, Assistant Professor, Department of Surgery, Anugrah Narayan Magadh Medical College and Hospital, Gaya.

Received: October 2019

Accepted: October 2019

\section{Introduction}

The use of cutting electrocautery instead of scalpel for skin incision is gradually gaining wide acceptance due to the observation that no change in wound complication rates or postoperative pain are reported with the use of cutting electrocautery. However, these studies include operations without the use of prosthetic materials during other general surgical procedures. The aim of this study was to evaluate the outcome of electrocautery skin incision, in terms of wound infection, pain, wound healing time, incision time \& blood loss, as compared to conventional scalpel skin incision, in tension free hernioplasty, exclusively. Despite the introduction of electrocautery (diathermy) about a century ago ${ }^{[2,3]}$ it is still used mostly for underlying dissection and hemostasis. ${ }^{[4]}$

Skin incisions with electrocautery are not frequent because of the hypothesis that (a) the application of extreme heat may result in significant postoperative pain and poor wound healing because of excessive tissue damage and scarring respectively and (b) skin incision with the use of electrocautery entails increases the risk of wound infection in the presence of an underlying prosthetic material. ${ }^{[5]}$ These presumptions stem from experimental and clinical studies that yielded varied reports. ${ }^{6-8}$ Modern electrosurgical units capable of delivering pure sinusoidal currents have evolved a change in this concept. The advantages are rapid hemostasis, faster dissection, and a reduced overall operative blood loss. ${ }^{[5,9,10]}$ Majority of studies had compared electrocautery and scalpel incision in terms of wound infection, postoperative pain, blood loss, duration of healing and postoperative wound complication in many surgical procedures ${ }^{[5-12]}$ but this study aims at comparison of same but in tension free hernioplasty operations exclusively, as it includes use of prosthetic material. The indices observed were the incision time, incisional blood loss, postoperative pain, wound healing and postoperative wound infection. The safety of diathermy in our environment is also considered. 


\section{Subjects and Methods}

This prospective study was conducted at ANMMCh, Gaya duration from January 2019 to September 2019. The study was approved by the institutional research committee. The participating patients were informed about the procedure and consent was taken from the subjects before starting the procedure. Informed consent taken as per protocol in the study. All patients admitted through surgical out-patient department for surgery were included for the study. All patients were consecutively allocated into two groups (A and B). Group A includes cases with skin incision by cutting electrocautery and group B includes skin incision with scalpel. The exclusion criteria were patients $<15$ years, patients who could not comprehend the pain scoring index for assessing postoperative pain due to communication barrier, all complicated hernias such as obstructed, strangulated and patients with co morbid conditions. All consenting patients within the inclusion criteria were consecutively enrolled in the study.

A total of 196 patients were included in this study. In group A; 98 patients had cutting electrocautery skin incision while 98 patients in group B had conventional scalpel skin incision. Group A patients had a surgical incision made with Electrosurgical unit in cutting mode, power of $5 \mathrm{~W}$ and $515 \mathrm{kHz}$ sinusoidal waveform while group B patients had surgical incision made with surgical blade. Prophylactic intravenous antibiotics were administered at induction of anesthesia. This was ceftriaxone alone or in combination with gentamycin. The prophylactic antibiotics were repeated for $48 \mathrm{hr}$ in these procedures. It was administered in the prophylactic setting for these clean procedures. The surgical incision in each case was made through skin, subcutaneous tissue, deep fascia and aponeurosis. The length and depth of each incision were measured using a sterile flexible ruler and the incision time was defined as the start of the skin incision till the intended operation site was reached with complete hemostasis and incisional blood loss being the blood loss that occurred strictly during the period of skin incision and this was calculated as the differences between the dry and wet weight of the swabs $(1 \mathrm{mg}=1 \mathrm{ml})$. No suction evacuation of blood was done while making the skin incision.

Postoperative analgesia was administered via the intravenous route using combination drug of diclofenac sodium and paracetamol for all patients for first 24 hour, and its oral form was used for next 3-5 days as per different cases. The pain assessment was done by surgical interns at fixed times on postoperative days 1, 2 and 3 using the verbal, numerical rating scale to assess the level of pain. Postoperative wound assessment both for healing and surgical site infection were assessed concurrently on the first 5 postoperative days and then at appointed times. The presence of a healing ridge with adequate tensile strength was used as an index of a healing wound while the Southampton grading system was used to denote the presence or absence of an infection. The perioperative occurrence of any adverse reaction or event whilst using the electrocautery machine was noted at surgery. The followup schedule included a review at the 4th 8th and 12th week respectively post operation. The findings from the patient's history, examination, body mass index (BMI), laboratory reports, imaging reports, operative and postoperative course were all recorded in the proforma. The cosmetic appearance of the scar was assessed as good, poor, contracted and formation of keloids by the operating surgeon. Statistical data analysis was done using SPSS version 10 trial version. Frequencies and proportions were used to summarize the variables while Chi-square and Student's t-test were used to test for association at $5 \%$ level of significance.

\section{Results}

A total of 196 patients were enrolled in this study. There were no significant demographic differences between the two groups (Table 1). We had a total of 182 males and 14 females. Their ages ranged from 16 to 73 years with a mean of $46 \pm 14.9$ years. Group A consisted of 98 patients (mean age-46 years [standard deviation (SD)-13.91; range 16-73 years]) and group B included 98 patients (mean age 45 years [SD-15.99; range 13-70 years]). The mean overall weight was $68.71 \mathrm{~kg}$ (SD-16.56), while the BMI for groups A and B were 24.66 (SD-7.83) and 25.17 (SD-5.80) $\mathrm{kg} / \mathrm{m} 2$ respectively which was not statistically significant. The mode of anesthesia was spinal anesthesia in all patients. Parenteral analgesia was administered in all patients for first 24 hour period and then as per complaint of pain which showed that group A patients were need only bid dosage of analgesics as mentioned before while Group B patients were need parenteral for 3-4 day and thereafter oral analgesics for another 3-4 days. The cumulative numerical rating scale score was lower in group A than in group B $(12.65 \pm 8.06$ vs. 17.12 \pm 9.49 , $\mathrm{P}=0.001)$. Although there was no statistical difference between the length $(\mathrm{P}=0.570)$ or depth $(\mathrm{P}=0.952)$ of incision in both groups, the incision time $(\mathrm{P}=0.001)$ and incisional blood loss $(\mathrm{P}=0.011)$ were significantly higher in group $\mathrm{B}$ patients (who had scalpel incisions). The wound healing time was comparable in both groups of patients with a delay in wound healing occurring in 2 (2\%) patients in group A and 3(3\%) patients in group B (Figure $1 \& 2)$. A total of 5 (2.5\%) patients had wound infection of which 2 cases in group $\mathrm{A}$ and 3 cases in group B respectively.

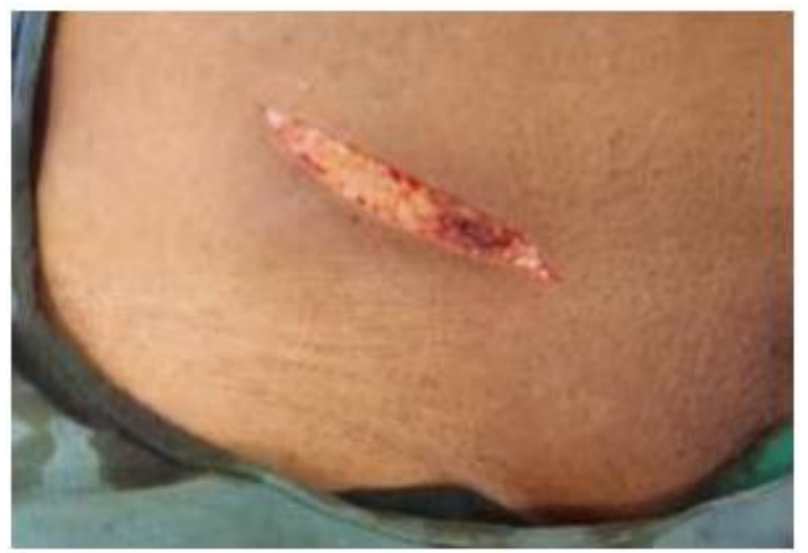

Figure 1: Scalpel Incision 


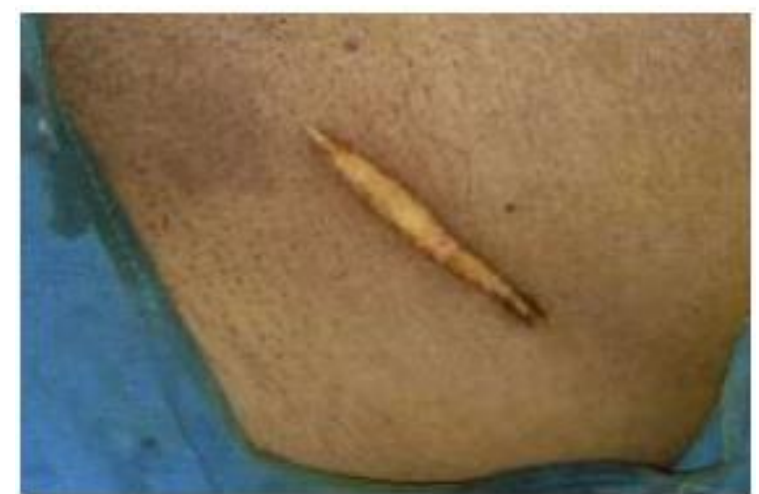

Figure 2: Electrocautery Incision

Table 1: Comparative data between two treatment groups

\begin{tabular}{|l|l|l|}
\hline & $\begin{array}{l}\text { Group A (Cautery } \\
\text { incision) } \\
\mathrm{n}=98\end{array}$ & $\begin{array}{l}\text { Group B(Scalpel } \\
\text { incision) } \\
\mathrm{n}=98\end{array}$ \\
\hline Age (Mean) & $46 \pm 13.9$ & $45 \pm 15.9$ \\
\hline BMI & $24 \pm 7.6$ & $25 \pm 5.8$ \\
\hline Incision time & $3-6 \mathrm{sec}$ & $4-7 \mathrm{sec}$ \\
\hline Incision length & $7-10 \mathrm{~cm}$ & $7-10 \mathrm{~cm}$ \\
\hline $\begin{array}{l}\text { Incisional blood } \\
\text { loss (gauze) }\end{array}$ & Partly socked & Fully socked \\
\hline Frequency of infection $(\%)$ & $2(2 \%)$ & $3(3 \%)$ \\
\hline Pain at incision site & Mild & Moderate \\
\hline Analgesics requirement in & & Inject able form \\
\hline $1^{\text {st }}$ day & Inject able form & $\begin{array}{l}\text { Inject able } \pm \text { oral } \\
\text { form }\end{array}$ \\
\hline $2^{\text {nd }}$ to $5^{\text {th }}$ day & Oral form & Good \\
\hline Cosmesis & Good &
\end{tabular}

\section{Discussion}

Electrosurgical unit (ESU) is the most common electrical equipment in the modern operating rooms. Surgeons are very comfortable to see a good ESU in the operation theater which is a part and parcel of surgeon's armamentarium. William T. Bovie, a biophysicist of Harvard Medical School, has been credited for commercially producing the first ESU, capable of cutting and coagulating the human tissues in the $1926^{[1,14]}$ ESU uses alternating high-frequency current. Frequency is the number of times an $\mathrm{AC}$ current reverses its direction in 1s and this is measured in cycles per second or hertz $(\mathrm{Hz})$. Radiofrequency $10,000 \mathrm{~Hz}$, can pass through the human body without causing stimulation of the muscle or nerve. An ESU uses radiofrequency of $100,000-10,000,000 \mathrm{~Hz}$ to cut, coagulate, and desiccate the tissues.

Surgical cut is made when the voltage between the cutting electrode and the tissue to be cut is sufficiently high to produce electric arcs between them (highfrequency AC). Peak voltage approximately $200 \mathrm{~V}$ is required to produce an arc.

Several studies have shown that electrocautery is increasingly being used for making skin incisions, securing hemostasis, dissecting tissue planes and cutting. ${ }^{[5,7,8,13]}$ It facilitates hemostasis, reduces overall intraoperative time and lastly produce a wound that heals similarly as one created by the scalpel. ${ }^{[5]}$ Despite these advantages; its use by surgeons for skin incisions in centers in developing countries including ours is still suboptimal. We can allude to the paucity of studies involving this group of patients in this region as the cause along with the old belief that electrocautery causes electric burns when used to make skin incisions, thus increasing the amount of devitalized tissue within the wound.

In Our study along with various other studies showed a significantly shorter incision time in the electrocautery group compared with the scalpel group. This is in contrast to the review by a previous study ${ }^{[18]}$ which suggested no added advantage with diathermy skin incision in terms of the incision time. The reduced ncisional blood loss in the diathermy group is in concordance with the findings in a similar study. ${ }^{[11,14,15]}$ There was only a slight difference in volume. The mean blood loss in the diathermy group was $1.53 \pm 3.84 \mathrm{ml}$ whilst theirs ${ }^{11}$ was $1.43 \pm 0.201 \mathrm{ml}$. This is due to the coagulative effect of diathermy on the micro-circulation of the area immediately adjoining the area of the incision.

In accordance with previous studies ${ }^{[5,14,15]}$ our results suggested a significantly reduced postoperative pain in the diathermy group. This is due to the thermal effect of diathermy on the sensory nerve fibers with the subsequent disruption of transmission of nerve impulses. Cell vaporization caused by the application of a pure sinusoidal current leads to immediate tissue and nerve necrosis without significantly affecting adjoining structures. Consequently, there is total or partial injury to the cutaneous nerves in the area of the surgical wound with a reduced postoperative pain profile in patients who had diathermy skin incisions. ${ }^{[17]}$ We however did not compare the postoperative pain with the various sites of surgery because the varied anatomic sites, along with the various amounts of underlying tissue dissection and inherent class of surgery may all affect the pain assessment score. This is a one of the limitations of this study.

In our study wound infection rate compared favorably with previous study. ${ }^{[7,14,15]}$ The conclusion was that it was not statistically significant. The overall outcome in this study in terms of early and late wound complications is comparable with other similar studies. ${ }^{[13-15,17]}$

The mean duration for complete wound healing was similar for both groups. This is similar to initial studies. ${ }^{[4,14,15]}$ There was no adverse effect noted during the course of our study attributable to the use of electrocautery.

\section{Conclusion}

In our study, we found that there is no significant difference in wound infection rates or scar cosmesis between the two treatment groups. Electrocautery significantly reduced the incision time and postoperative wound pain. A trend toward less incisional blood loss from skin incisions made with electrocautery was noted. As previous studies have not shown adverse wound 
outcomes using this technique, and considering the safety concerns for theatre staff when the scalpel is used, the routine use of cutting electrocautery for skin incisions in tension free hernioplasty surgery is justified.

\section{References}

1. Barrett SL, Vella JM, Dellon AL. Historical development of bipolar coagulation. Microsurgery. 2010;30(8):667-9.

2. Wicker P. Electrosurgery - Part I. The history of diathermy. NATNEWS. 1990;27:6-7.

3. Memon MA. Surgical diathermy. Br J Hosp Med. 1994;52:403-8.

4. Shamim M. Diathermy vs. scalpel skin incisions in general surgery: double-blind, randomized, clinical trial. World J Surg. 2009;33:1594-9.

5. Kearns SR, Connolly EM, McNally S, McNamara DA, Deasy J. Randomized clinical trial of diathermy versus scalpel incision in elective midline laparotomy. Br J Surg. 2001;88:41-4.

6. Soballe PW, Nimbkar NV, Hayward I, Nielsen TB, Drucker WR. Electric cautery lowers the contamination threshold for infection of laparotomies. Am J Surg.1998;175:263-6.

7. Groot G, Chappell EW. Electrocautery used to create incisions does not increase wound infection rates. Am J Surg. 1994;167:6013.

8. Hussain SA, Hussain S. Incisions with knife or diathermy and postoperative pain. Br J Surg. 1988; 75:1179-80.

9. Chalya PL, Mchembe MD, Mabula JB, Gilyoma JM. Diathermy versus scalpel incision in elective midline laparotomy: A prospective randomized controlled clinical study. East and Cent. Afr J Surg.
2013;18:71-7.

10. Kumar V, Tewari M, Shukla HS. A comparative study of scalpel and surgical diathermy incision in elective operations of head and neck cancer. Indian J Cancer. 2011;48:216-9.

11. Arsalan S, Muhammad F, Athar AS, Sohail R. Elective midline laparotomy; comparison of diathermy and scalpel incisions. Prof Med J. 2011;18:106-11.

12. Ozdogan M, Yilmaz KB, Ozaslan C, Gurer A, Gulbahar O, Ersoy E. Scalpel versus electrocautery dissection: The effect on wound complication and pro inflammatory cytokines levels in wound fluid. Turk J Med Sci. 2008;38:111-6.

13. Franchi M, Ghezzi F, Benedetti-Panici PL, Melpignano M, Fallo $\mathrm{L}$, Tateo $\mathrm{S}$ et al. A multicentre collaborative study on the use of cold scalpel and electrocautery for midline abdominal incision. Am J Surg. 2001;181:128-32.

14. Vedbhushan ST, Mulla MA, Haroonrasid, Chandrashekhar DM. Surgical incision by high frequency cautery. Indian J Surg. 2013;75(6):440-3.

15. Ayandipo OO, Afuwape OO, Irabor D, Oluwatosin OM, Odigie V. Diathermy versus scalpel incision in a heterogeneous cohort of general surgery patients in a Nigerian teaching hospital. Niger $\mathbf{J}$ Surg. 2015;21(1):43-7.

16. Dixon AR, Watkin DF. Electrosurgical skin incision versus conventional scalpel: a prospective trial. J R Coll Surg Edinb. 1990;35:299-301.

17. Chrysos E, Athanasakis E, Antonakakis S, Xynos E, Zoras O. A prospective study comparing diathermy and scalpel incisions in tension-free inguinal hernioplasty. Am Surg. 2005;71:326-9.

18. Telfer JR, Canning G, Galloway DJ. Comparative study of abdominal incision techniques. Br J Surg. 1993;80:233-5.

Copyright: (C) the author(s), 2019. It is an open-access article distributed under the terms of the Creative Commons Attribution License (CC BY 4.0), which permits authors to retain ownership of the copyright for their content, and allow anyone to download, reuse, reprint, modify, distribute and/or copy the content as long as the original authors and source are cited.

How to cite this article: Ranjan SK, Kumar S. Comparative Evaluation of Wound Outcome between Electrocautery and Scalpel Incision. Acad. J Surg. 2019;2(2):23-26.

DOI: dx.doi.org/10.21276/ajs.2019.2.2.6 